\title{
Chemosensitivity of human MCF-7 breast cancer cells to diastereoisomeric diaqua(1,2-diphenylethylenediamine) platinum(II) sulfates and specific platinum accumulation*
}

\author{
Herta Reile1, Günther Bernhardt'1, Marion Koch'1, Helmut Schönenberger ${ }^{1}$, Michael Hollstein², and Franz Lux ${ }^{2}$ \\ ${ }^{1}$ Universität Regensburg, Institut für Pharmazie, Sonderforschungsbereich 234, Universitätsstraße 31, W-8400 Regensburg, FRG \\ 2 Institut für Radiochemie der Technischen Universität München, Walther-Meißner-Straße 3, W-8046 Garching, FRG
}

Received 14 September 1991/Accepted 5 February 1992

Summary. Cisplatin, raceme-diaqua[1,2-bis(4-fluorophenyl)ethylenediamine]platinum(II) sulfate (compound I), meso-diaqua[1,2-bis(4-fluorophenyl)ethylenediamine]platinum(II) sulfate (compound II), and meso-diaqua[1,2bis(2,6-dichloro-4-hydroxyphenyl)ethylenediamine]platinum(II) sulfate (compound III) were compared with regard to their effect on the MCF-7 breast cancer cell line in vitro. At equimolar concentrations ( $5 \mu \mathrm{M})$, cisplatin, compound $\mathrm{I}$, and compound II were equiactive after $231 \mathrm{~h}$ drug exposure, whereas compound III was ineffective. Although compounds I and II showed markedly greater inactivation than did cisplatin after $6 \mathrm{~h}$ incubation with culture medium, compound I (but not compound II) exhibited antitumor activity equivalent to that of cisplatin when cells were exposed to the drugs for $6 \mathrm{~h}$. Platinum measurements by neutron-activation analysis revealed that compound I was selectively and rapidly accumulated by MCF-7 cells, resulting in a high degree of DNA platination within the first few hours of drug exposure. However, when the drug-exposure period was long enough, platinum enrichment was not reflected in an overall difference in the cytotoxicity of compound I vs cisplatin. Nevertheless, compound I should be superior to cisplatin in vivo, provided that effective plasma levels can be maintained for about $6 \mathrm{~h}$.

\section{Introduction}

Cisplatin is the primary building block in regimens used to treat human testicular carcinoma, and it produces high response rates in patients suffering from head and neck, ovarian, bladder, and small-cell lung cancers. However,

* This work was supported by the Deutsche Forschungsgemeinschaft and the Mattbias Lackas Stiftung für Krebsforschung. Financial support was also provided by the Fonds der Chemischen Industrie

Offprint requests to: Dr. Günther Bernhardt, Institut für Pharmazie, Universitätsstraße 31, W-8400 Regensburg, FRG the clinical effectiveness of cisplatin is greatly compromised by its severe undesirable side effects and by the complete refractoriness of some tumors to cisplatin treatment. These factors have stimulated the synthesis and evaluation of many new platinum complexes $[13,19]$ based on the desire to find compounds that produce reduced toxicity and exhibit a broader spectrum of activity, particularly in clinical diseases in which cisplatin has not demonstrated a therapeutic effect (e.g., mammary and prostatic carcinomas).

Stereoisomeric (1,2-diphenylethylenediamine)platinum(II) complexes have been reported to exert marked antileukemic activity [11, 20, 33]. Quite recently, our group has described diastereoisomeric ring-substituted (1,2-diphenylethylenediamine)platinum(II) complexes that have been highly effective against several rodent tumor models in vivo. Meso-configurated [1,2-bis(2,6dichloro-4-hydroxyphenyl)ethylenediamine]platinum(II) complexes exhibit hormone-like properties and have been found to produce high response rates in the hormone-sensitive rodent tumor models MXT (M 3.2) mammary carcinoma of the $\mathrm{B} 6 \mathrm{D} 2 \mathrm{~F}_{1}$ mouse, DMBA-induced mammary carcinoma of the Sprague-Dawley rat [14, 29], and Dunning R 3327 and Noble prostatic carcinoma of the rat [27]. Diastereoisomeric diaqua[1,2-bis(4-fluorophenyl)ethylenediamine]-platinum(II) salts, which lack estrogenic activity, produce strong inhibition of the ovarian-dependent MXT (M 3.2) mammary carcinoma of the B6D2F 1 mouse. In contrast to the racemic compounds, the meso-configurated complexes are also active against the hormone-independent MXT (M 3.2)-OVEX mammary carcinoma of the $\mathrm{B} 6 \mathrm{D} 2 \mathrm{~F}_{1}$ mouse [25]. Antitumor agents that effect estrogen-receptor-positive and -negative breast cancers would be of enormous therapeutic value, since drugs of this type should delay (or perhaps prevent) the development of resistance to hormonal therapy caused by the proliferation of hormone-insensitive tumor cell clones.

Interestingly, the aforementioned ring-substituted diaqua(1,2-diphenylethylenediamine)platinum(II) salts are highly active against rodent breast cancer models, although such complexes are charged species. It is generally ac- 
cepted that ionized compounds cannot diffuse freely across membrane barriers [22]. Thus, the literature reporting on the antitumor activity of charged complexes is scanty $[6,7,16]$.

Due to their unrealistically high sensitivity to cisplatin, murine mammary carcinomas have been suspected to be inappropriate models for testing of platinum analogues $[30,31]$, since it is well known that cisplatin is ineffective in the therapy of human breast cancer. Therefore, according to the new test strategy of the National Cancer Institute, human (breast) cancer models are preferable.

In the present study, we laid the foundations for the further testing of these compounds on human mammary carcinomas implanted into nude mice, by determining the conditions for an optimal in vivo schedule. For this purpose, we compared the diastereoisomeric diaqua[1,2-bis(4fluorophenyl)ethylenediamine]platinum(II) sulfates (compounds I and II) and meso-diaqua[1,2-bis(2,6-dichloro4-hydroxyphenyl)ethylenediamine]platinum(II) sulfate (compound III) with cisplatin in terms of their stability in culture medium, their dose-dependent antitumor activity, the time required to obtain a cytocidal drug effect, the kinetics of platinum accumulation by the hormone-sensitive MCF-7 human breast cancer cell line $[2,3]$ and the extent of DNA platination.

\section{Materials and methods}

\section{Chemicals}

Reagents (A-grade purity) were obtained from Merck (Darmstadt, FRG). $N$-Hexamethylpararosaniline (crystal violet) and trypsin $(1: 250, \mathrm{v} / \mathrm{v})$, were purchased from Serva (Heidelberg, FRG). N,N-Dimethylformamide (DMF, spectrophotometric grade) was obtained from Aldrich (Steinheim, FRG). Guanidinium hydrochloride, dithioerythritol (DTE), and sodium pyruvate were supplied by Sigma (München, FRG). Bio-rad protein-assay dye-reagent concentrate was obtained from Bio-rad Laboratories (München, FRG), and human serum albumin (HSA) was supplied by Behring (Marburg, FRG). Millipore-filtered water was used throughout the experiments.

\section{Cell culture}

The human MCF-7 breast cancer cell line [28] was obtained from the American Type Culture Collection (ATCC, Rockville, Md., USA). Cellline banking and quality control was performed according to the seed stock concept reviewed by Hay [12]. The MCF-7 (ATCC number HTB 22) cells were maintained in MEM Eagle's medium (Sigma, München, FRG) containing L-glutamine, $\mathrm{NaHCO}_{3}(2.2 \mathrm{~g} / \mathrm{l})$, sodium pyruvate $(110 \mathrm{mg} / \mathrm{l})$, gentamycin $(50 \mathrm{mg} / \mathrm{l}$; Sebio, Walchsing, FRG), and $10 \%$ fetal calf serum (FCS; Gibco, Eggenheim, FRG) using 75- $\mathrm{cm}^{2}$ culture flasks (Falcon Plastics 3023) in a water-saturated atmosphere (95\% air $/ 5 \% \mathrm{CO}_{2}$ ) at $37^{\circ} \mathrm{C}$. The cells were serially passaged weekly following trypsinization using $0.05 \%$ tryp $\sin / 0.02 \%$ ethylenediaminetetraacetic acid (EDTA; Boehringer, Mannheim, FRG). Mycoplasma contamination was routinely monitored, and only Mycoplasma-free cultures were used.

\section{Drugs}

Cisplatin (gold label) was obtained from Aldrich (Steinheim, FRG). The structures of the diaqua(1,2-diphenylethylenediamine)platinum(II) sulfates are shown in Fig. 1. Their synthesis as well as their chemical and
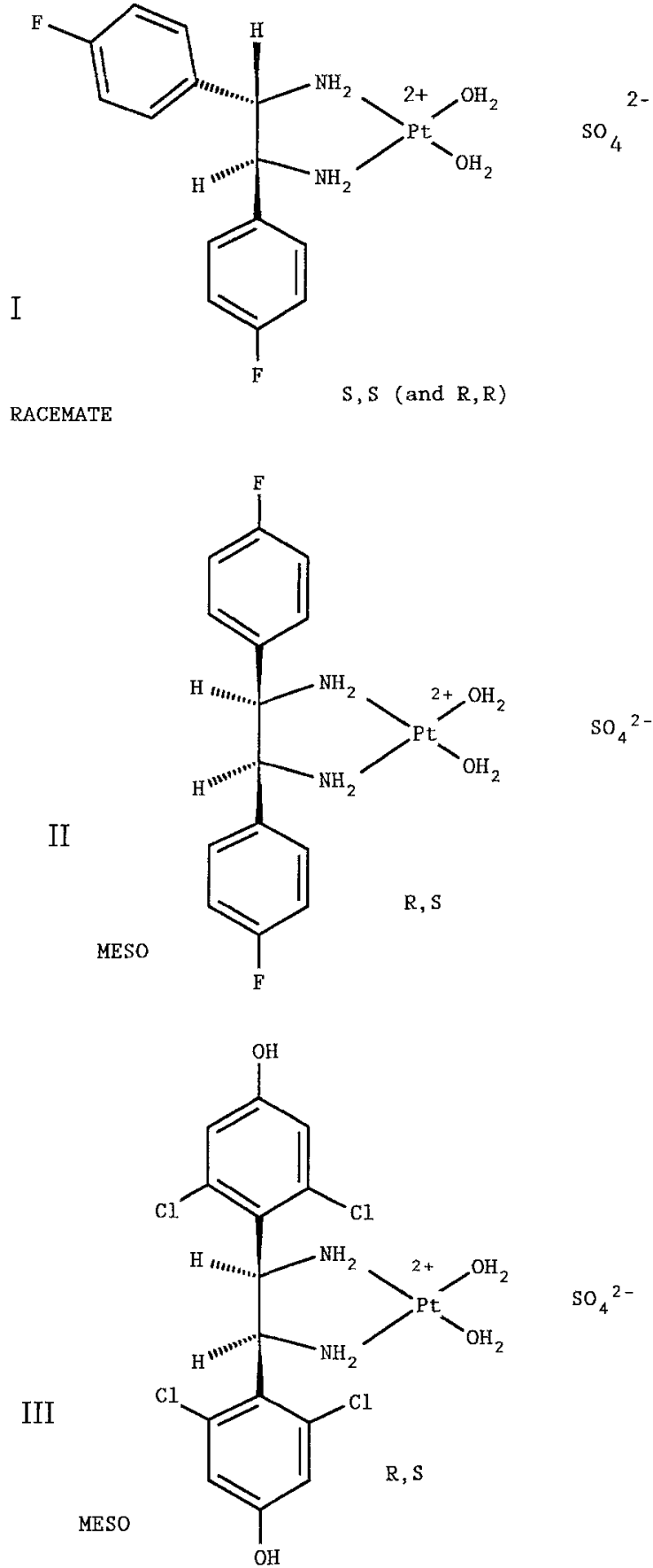

Fig. 1. Structures of the cisplatin analogues used in the chemosensitivity and accumulation studies. Compound I: raceme-diaqua[1,2-bis(4fluorophenyl)ethylenediamine]platinum(II) sulfate. Compound II: mesodiaqua[1,2-bis(4-fluorophenyl)ethylenediamine]platinum(II) sulfate. Compound III: meso-diaqua[1,2-bis(2,6-dichloro-4-hydroxyphenyl)ethylenediamine]platinum(II) sulfate

(some) biological properties have been described elsewhere $[14,18,24$, 25]. Despite the ionic nature of the diaqua(1,2-diphenylethylenediamine)platinum(II) sulfates, their water solubility is quite low because of the contribution of the large, hydrophobic neutral ligand. Therefore, for all platinum complexes, $10-\mathrm{mm}$ stock solutions were prepared in DMF. After appropriate dilution of the stock solution, feed solutions were made. The drugs (i.e., the feed solutions) were added to the culture medium such that the final DMF concentration was $0.1 \%(\mathrm{v} / \mathrm{v})$. 


\section{Chemosensitivity assay}

We have recently reported the principle and the applications of the kinetic crystal violet assay $[2,23]$. In brief, cells were seeded $(100 \mu \mathrm{l} /$ well) in 96-well flat-bottomed microtitration plates (Falcon Plastics 3075). After $48 \mathrm{~h}$ (corresponding to an absorbance of approx. 0.2), the medium was carefully removed by suction and replaced by fresh medium $(200 \mu 1 /$ well) containing drug (feed solutions were diluted $1: 1,000$ with culture medium) or pure solvent. On each plate, 16 wells served as controls and 16 wells were used per drug concentration. After various periods of incubation, the culture medium was shaken off and the cells were fixed with $100 \mu \mathrm{l} 1 \%$ glutardialdehyde in phosphate-buffered saline (PBS) per well for $15 \mathrm{~min}$. The fixative was replaced by $150 \mu \mathrm{l}$ $\mathrm{PBS} /$ well and the plates were stored in the refrigerator $\left(4^{\circ} \mathrm{C}\right)$. At the end of the experiment, all trays were simultaneously stained with $0.02 \%$ aqueous crystal violet solution $(100 \mu \mathrm{l} /$ well $)$ for $30 \mathrm{~min}$. Excess dye was removed by rinsing the trays with water for $15 \mathrm{~min}$. The stain bound by the cells was redissolved in $70 \%$ ethanol $(180 \mu \mathrm{l} / \mathrm{well})$ during shaking of the microplates for about $3 \mathrm{~h}$. Absorbance (a parameter proportional to cell mass) was measured at $578 \mathrm{~nm}$ using a Biotek 309 Autoreader (Tecnomara, Fernwald, FRG). Drug effects were expressed as corrected $\mathrm{T} / \mathrm{C}$ values for each group (in percent) according to the equation

$\mathrm{T} / \mathrm{C}_{\text {corr }}=\left(\mathrm{T}-\mathrm{C}_{0}\right) /\left(\mathrm{C}-\mathrm{C}_{0}\right) \times 100$,

where $T$ represents the mean absorbance of the treated cells; $C$, the mean absorbance of the controls, and $\mathrm{C}_{0}$, the mean absorbance of the cells at time zero, when the drug was added.

\section{Stability determination}

The stability of the diastereoisomeric diaqua[1,2-bis(4-fluorophenyl)ethylenediamine]platinum(II) sulfates (compounds I and II) and cisplatin in the presence of nucleophiles was evaluated according to the following experimental protocol:

1. The platinum complexes (final concentration, $5 \mu \mathrm{M}$ ) were preincubated in culture medium (containing 10\% FCS) for 1,6 , and $48 \mathrm{~h}$ under standard conditions (water-saturated atmosphere comprising $95 \%$ air $/ 5 \% \mathrm{CO}_{2}$ at $37^{\circ} \mathrm{C}$ ).

2. The loss of activity against MCF-7 cells caused by preincubation was subsequently measured by the crystal violet chemosensitivity assay.

\section{Accumulation studies}

Drug treatment and sample preparation. For platinum-accumulation studies, cells (in passage 160) were grown in $175-\mathrm{cm}^{2}$ culture flasks (Falcon Plastics 3028). When the cells had approached confluency, the culture medium was aspirated and replaced with fresh medium containing $5 \mu \mathrm{M}$ platinum complex or $0.1 \%$ DMF (blank), whereby $50 \mu \mathrm{l}$ feed solution was added to $50 \mathrm{ml}$ culture medium. Four culture flasks were used for the blanks over 15-s, 15-min, 30-min, 45-min, and 60-min incubation periods, whereas three flasks were prepared for $2-, 4-, 12-$, and 24-h drug exposure periods. Except for the blanks and the 15-s samples, which were processed immediately, all culture flasks were returned to the incubator. At appropriate time points, the flasks were removed from the incubator, the medium was aspirated, and the cells were thoroughly washed twice with $10 \mathrm{ml} 0.9 \% \mathrm{LiCl}$ solution. The cells were harvested after treatment with $3 \mathrm{ml} 0.05 \%$ trypsin (ca. $1 \mathrm{~min}$, trypsin dissolved at $1: 250, \mathrm{v} / \mathrm{v}$, in $0.9 \% \mathrm{LiCl}$ ) in $5 \mathrm{ml} 0.9 \% \mathrm{LiCl}$. For complete removal of the cells, the culture flasks were rinsed with an additional $5 \mathrm{ml} 0.9 \% \mathrm{LiCl}$ solution. At each time point, the cells were pooled and centrifuged at $250 \mathrm{~g}$ for $15 \mathrm{~min}$. The pellet was resuspended in $10 \mathrm{ml} 0.9 \% \mathrm{LiCl}$ and centrifugation was repeated. Finally, the washing solution was decanted from the cell pellet. Following vortexing, the homogeneous cell suspensions (ca. $800 \mu 1$ ) were split. About two-thirds of each cell suspension was transferred into quartz ampoules for platinum and an aliquot was used for protein measurement. All samples were weighed.

Platinum analysis. Platinum was determined by neutron-activation analysis (NAA). Samples (300-600 mg cell suspension) were lyophilized in ampoules made of ultrapure quartz (Suprasil AN, Heraeus Quarzschmelze GmbH, Hanau, FRG). The cleaning of the ampoules has been described elsewhere [17]. The sealed ampoules were irradiated together with quartz ampoules containing hexachloroplatinum(IV) acid as a standard in the Forschungsreaktor München at a thermal neutron flux of $2 \times 1,013 \mathrm{~cm}^{-2} \mathrm{~s}^{-1}$ for $50 \mathrm{~h}$. After irradiation and a decay time of $2-3$ days, the ampoules were cleaned on the outside [17]. The gamma spectra of the samples and the standards were recorded [counting equipment: $130-\mathrm{cm}^{3}$ intrinsic coaxial Ge detector $(2.1-\mathrm{keV}$ resolution and $27 \%$ relative efficiency, both for the $1,332.50-\mathrm{keV}$ gamma line of ${ }^{60} \mathrm{Co}$ ); main amplifier, Silena model 7611; ADC Silena model 7423 UHS; memory buffer module, Silena $7329-16 \mathrm{~K}$; personal computer, Silena AT/03/CO].

For evaluation of the gamma spectra, emulation software MMB3 was used. The ampoules were positioned with their axes parallel to the detector surface at a distance of $4-10 \mathrm{~cm}$. ${ }^{199} \mathrm{Au}$ was chosen as the reference nuclide for platinum [32]. The evaluation was based on the $158.37-\mathrm{keV}$ and on the $208.20 \mathrm{-keV}$ gamma lines of ${ }^{199} \mathrm{Au}$. The detection limit for platinum lay between $1 \mathrm{ng}$ (4-cm distance) and $2 \mathrm{ng}(10-\mathrm{cm}$ distance)/sample.

Protein determination. Samples (50-200 mg cell suspension) were dried at $80^{\circ} \mathrm{C}$, and total protein was dissolved in $300 \mu$ d denaturation buffer ( $6 \mathrm{~m}$ guanidinium hydrochloride, $50 \mathrm{~mm}$ DTE, $0.5 \mathrm{M}$ TRIS/HCl, $\mathrm{pH}$ 8.5). Protein was measured after appropriate dilution with denaturation buffer according to the method of Bradford [5]. For calibration, HSA $(50-800 \mu \mathrm{g} / \mathrm{ml})$ was dissolved in denaturation buffer.

Correlation of cell number and protein content. Cells were cultured and harvested by routine techniques. After three cycles of washing (PBS) and centrifugation, cells were suspended in PBS and various dilutions $(n=6)$ were prepared. Protein was measured as described above. In parallel, the cell number was determined using a hemocytometer by counting the nuclei remaining after lysis of the cells with $0.1 \%$ citric acid containing $0.02 \%$ crystal violet.

Determination of cell volume. The diameters of trypsinized MCF-7 cells $(n=50)$ were determined in culture medium using an Olympus BH-2 microscope equipped with an SPlan $40 \mathrm{PL}$ (phase-contrast) objective (Olympus Optical Co. Ltd., Tokyo, Japan). The microscopic image was focused through an NFK $2.5 \times$ photoeyepiece to a Panasonic F10 CCD videocamera (Matsushita Communication Industrial Co., Ltd., Osaka, Japan). For image analysis, the video signal was transformed in a PIP512/1024A video digitizer board (Matrox Electronic Systems Ltd., Quebec, Canada) installed in an Olivetti M24 personal computer (Ivrea, Italy) and then visualized on a Sony PVM-1371 QM video monitor (Tokyo, Japan). Cell diameters were marked using a mouse and then automatically measured by an image-processing program written in TURBO PASCAL. The volumes of 50 cells were calculated from the diameters, assuming a spherical cell shape.

Calculation of cellular platinum concentration. The analysis of all cell suspensions provided the following data: the mass of the cell suspension used for NAA ( $\left.m_{\mathrm{csp}, \mathrm{NAA}}\right)$, the platinum mass found in the NAA sample $\left(m_{\mathrm{Pt}, \mathrm{csp}, \mathrm{NAA}}\right)$, and the protein content of the cell suspension ( $\left.w_{\mathrm{prt}, \mathrm{csp}}\right)$. For calculations of cell-associated platinum $\left(c_{\mathrm{Pt}, \mathrm{c}}\right)$ on a molar basis, the value for the mean protein-mass concentration in the cells $\left(\bar{p}_{\mathrm{pr} t}, \mathrm{c}\right)$ must be known; $\bar{p}_{\text {prt,c }}$ is defined as the mean protein mass per cell divided by the mean cell volume. The mean protein-mass concentration was determined in a separate experiment as described above. Cell-associated platinum expressed in moles per liter was calculated by the equation

$c_{\mathrm{Pt}, \mathrm{c}}=\left(m_{\mathrm{Pt}, \mathrm{esp}, \mathrm{NAA}} / M_{\mathrm{Pt}}\right) \times\left(\bar{p}_{\mathrm{prt}, \mathrm{c} / w_{\mathrm{prt}, \mathrm{csp}}} \times m_{\mathrm{csp}, \mathrm{NAA}}\right)$,

where $M_{\mathrm{Pt}}$ represents the molar mass of platinum.

DNA platination. MCF-7 cells (204th passage) were treated with $5 \mu \mathrm{M}$ platinum complex as described above. At the time points indicated in Table 1, the cells from two $175-\mathrm{cm}^{2}$ flasks were pooled and the DNA was isolated according to the procedure described by Fichtinger-Schepman and collegues [9], including an additional high-salt step using $7.5 \mathrm{M}$ 

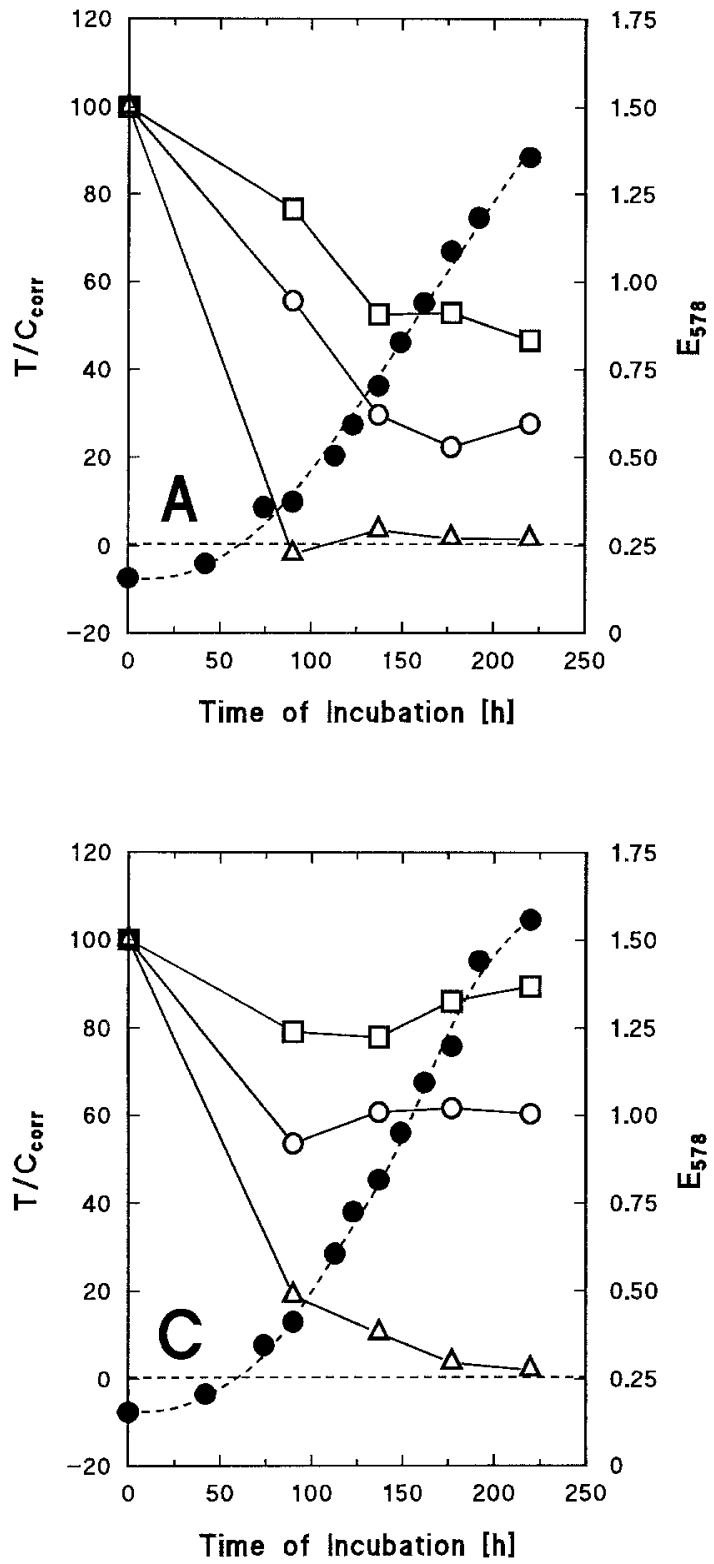

Fig. 2 A - D. Effect of drug concentration on cell proliferation following long-term incubation of MCF-7 cells (passage 155) with the platinum complexes shown in Fig. 1. $\square, 0.5 \mu \mathrm{M} ; \mathrm{O}, 1 \mu \mathrm{M} ; \triangle, 5 \mu \mathrm{M} ; \boldsymbol{\Lambda}, 10 \mu \mathrm{M}$; -, proliferation kinetics of the corresponding controls (absorbance at $578 \mathrm{~nm}$ ). A Cisplatin. B Raceme-diaqua[1,2-bis(4-fluorophenyl)ethyl-

Table 1. Kinetics of DNA platination during treatment of 204th-passage MCF-7 cells with $5 \mu \mathrm{M}$ cisplatin and diaqua(1,2-diphenylethylenediamine)platinum(II) sulfates

\begin{tabular}{llllr}
\hline Time (h) & \multicolumn{4}{l}{ Number of base pairs/platinum atom } \\
\cline { 2 - 5 } & \multicolumn{2}{l}{ Compound } & & \\
\cline { 2 - 5 } & Cisplatin & I & II & \multicolumn{1}{l}{ III } \\
\hline 4 & 99,400 & 17,500 & 415,000 & $1,140,000$ \\
12 & 65,200 & 19,900 & 77,700 & 343,000 \\
24 & 64,100 & 22,400 & 38,800 & 86,000 \\
\hline
\end{tabular}
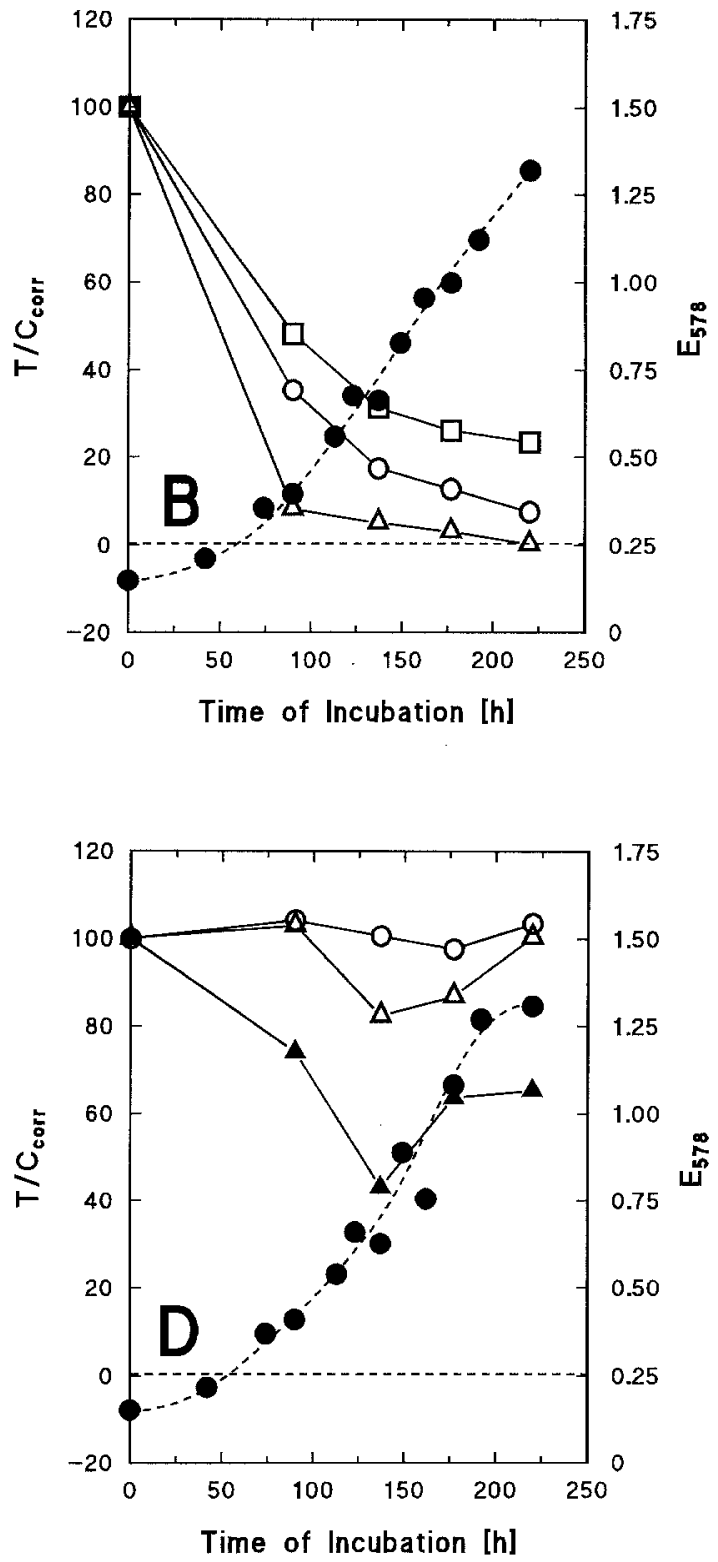

enediamine]platinum(II) sulfate (compound I), C Meso-diaqua[1,2bis(4-fluorophenyl)ethylenediamine]platinum(II) sulfate (compound II). D Meso-diaqua[1,2-bis(2,6-dichloro-4-hydroxyphenyl)ethylenediamineplatinum(II) sulfate (compound III)

ammonium acetate. The samples were prepared in duplicate. DNA purity and concentration were determined by routine fluorescence and UV spectrophotometric methods [4]. DNA-associated platinum was measured by NAA.

\section{Results}

\section{Permanent drug exposure and chemosensitivity}

MCF-7 cells (in passage 155) were treated with compounds I-III and cisplatin in three concentrations $(0.5,1$, and $5 \mu \mathrm{M}$ for compound I, compound II, and cisplatin, and 1,5 , and $10 \mu \mathrm{M}$ for compound $\mathrm{III}$ ) at $48 \mathrm{~h}$ after seeding. In this experiment, the drug- (and vehicle-) containing culture 

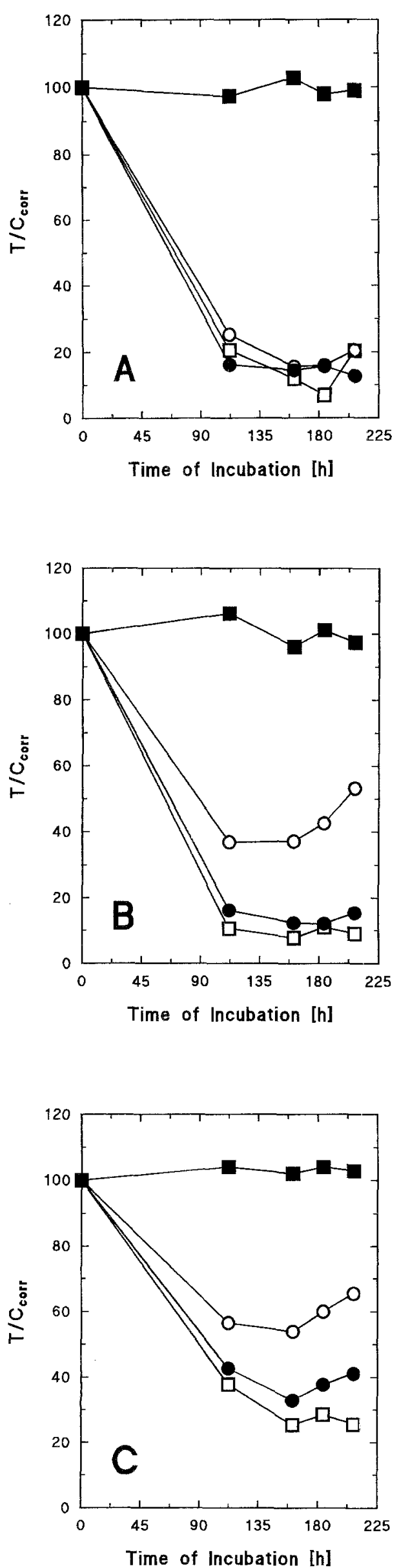

Fig. $3 \mathrm{~A}-\mathrm{C}$. Effect of preincubation with cisplatin and diastereoisomeric diaqua[1,2-bis(4-fluorophenyl)ethylenediamine]platinum(II) sulfates on inhibition of the proliferation of MCF-7 (passage 183) breast cancer cells. Prior to the routine chemosensitivity assay, the platinum complexes $(5 \mu \mathrm{M})$ were incubated with culture medium containing $10 \%$ FCS. $\square$, No preincubation;, $1 \mathrm{~h}$ preincubation; $O, 6 \mathrm{~h}$ preincubation; $\mathbf{\square}, 48 \mathrm{~h}$ preincubation. A Cisplatin. B Raceme-diaqua[1,2-bis(4-fluorophenyl)ethylenediamine]platinum(II) sulfate (compound I). C Meso-diaqua[1,2bis(4-fluorophenyl)ethylenediamine]platinum(II) sulfate (compound II)

media were left unchanged throughout the incubation period. The results are summarized in Fig. 2. In these plots of $\mathrm{T} / \mathrm{C}_{\mathrm{cor}} \mathrm{vs}$ time of incubation, time zero indicates the time at which drug was added. According to Eq. 1, any growth curve for a drug-treated cell population can be reconstructed from the $\mathrm{T} / \mathrm{C}_{\text {corr }}$ values and the growth-curve data of the corresponding control [2].

For compounds I and II and cisplatin, a clear-cut dosedependent inhibition of cell proliferation that resulted in final equiactivity at $5 \mu \mathrm{M}$ was observed, whereas compound III was ineffective at 1 and $5 \mu \mathrm{M}$. Even at a very high dose $(10 \mu \mathrm{M})$, compound III produced only weak, transient effects, i.e., the culture recovered and regained complete reproductive integrity. The extent of dose dependence decreased from coumpound II (flat dose-response relationship) to compound I to cisplatin (steep dose-response relationship) and was paralleled by an increase in antiproliferative activity for the 0.5- and 1- $\mu \mathrm{M}$ doses. At the highest concentration $(5 \mu \mathrm{M})$, all three platinum complexes produced $\mathrm{T} / \mathrm{C}_{\mathrm{corr}}$ values of zero (i.e., $100 \%$ inhibition of net cell proliferation) toward the end of the incubation period. Surprisingly, in comparison with the activity of its mesoconfigurated counterpart (compound II), the onset of action of the racemic complex (compound I) was considerably faster.

Stability of cisplatin, raceme-, and meso-diaqua[1,2bis(4-fluorophenyl)ethylenediamine Iplatinum(II) sulfate in culture medium

For all complexes, a complete loss of activity was observed after $48 \mathrm{~h}$ preincubation (Fig. 3) due to inactivation processes resulting from reactions with nucleophiles such as amino acids and serum proteins. Whereas cisplatin displayed full activity after $6 \mathrm{~h}$ preincubation, compounds I and II showed considerable inactivation. Within the range of experimental error, there was no difference in the reactivities of the diastereoisomers.

\section{Short-term drug exposure and chemosensitivity}

To determine the duration of drug exposure required to achieve optimal inhibitory effects, MCF-7 cells were incubated in the presence of $5 \mu \mathrm{M}$ cisplatin, compound $\mathrm{I}$, and compound II for 4,6 , and $12 \mathrm{~h}$. After the indicated periods of drug exposure, the platinum complexes were removed by medium exchange and the $\mathrm{T} / \mathrm{C}_{\text {corr }}$ values were determined at various times during incubation of the cultures in 

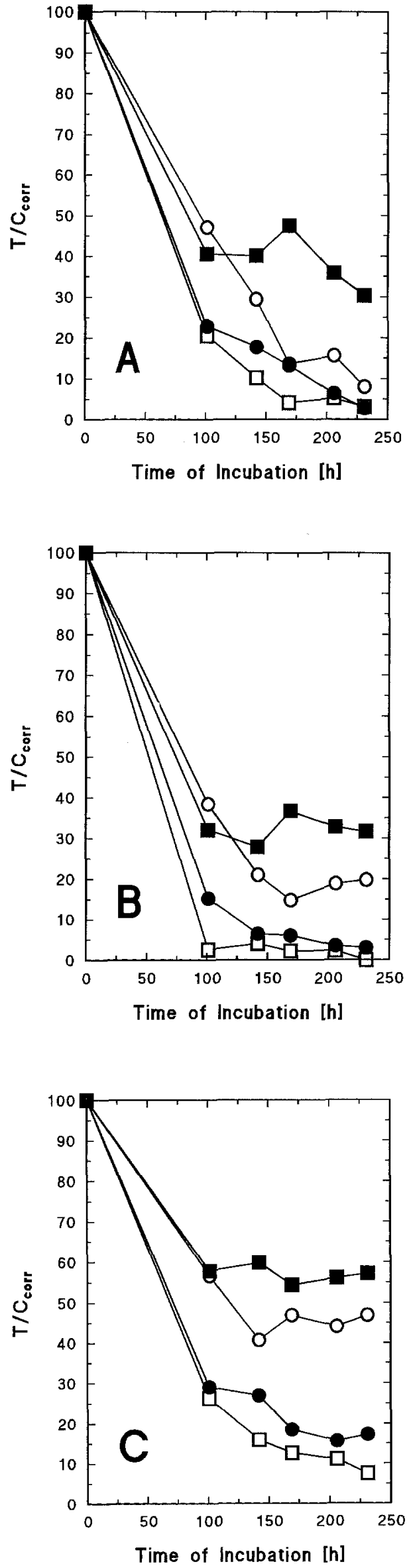

Fig. 4A-C. Effect of the duration of drug exposure on the proliferation of MCF-7 cells (passage 194). First, the cells were incubated for 4 ( $\boldsymbol{\square}$ ), $6(\mathrm{O})$, and $12 \mathrm{~h}(\mathrm{)})$ in the presence of $5 \mu \mathrm{M}$ platinum complex; then, the drug-containing media were replaced by fresh drug-free culture medium $(\mathrm{t}=0)$ and the cells were incubated under standard conditions for $231 \mathrm{~h}$. $\square$, Permanent incubation of the cells in the presence of drug $(231 \mathrm{~h})$. A Cisplatin. B Raceme-diaqua[1,2-bis(4-fluorophenyl)ethylenediamine]platinum(II) sulfate (compound I). C Meso-diaqual1,2-bis(4fluorophenyl)ethylenediamine]platinum(II) sulfate (compound II)

fresh medium. Figure 4 shows direct proportionality for the duration of drug exposure and the inhibition of cell proliferation. All three platinum complexes displayed maximal activity after $12 \mathrm{~h}$. It is noteworthy that after $6 \mathrm{~h}$ incubation, compound I and cisplatin produced comparable $\mathrm{T} / \mathrm{C}_{\mathrm{corr}}$ values (around $20 \%$ ), although compound I was definitely less stable in culture medium (cf. Fig. 3). In contrast, $12 \mathrm{~h}$ drug exposure was necessary for its mesoconfigurated counterpart (compound II) to become equiactive at the given concentration. In addition, the manifestation of cytotoxicity was markedly faster for compound I than for cisplatin or compound II.

\section{Platinum accumulation by $M C F-7$ cells}

For estimations of cell-associated platinum on a molar basis, the following parameters were determined in a separate experiment. The mean diameter of the cells suspended in culture medium was $16.2 \pm 3.0 \mu \mathrm{m}$. The volumes of 50 cells were calculated from the corresponding cell diameters: the mean cell volume was $2.46 \pm 1.61 \mathrm{pl}$. The mean protein mass per cell was $0.205 \pm 0.021 \mathrm{ng}$. These data yielded a mean protein-mass concentration in the cell of $83.5 \pm 55.5 \mathrm{~g} \mathrm{1}^{-1}$.

MCF-7 (passage 160) cells were incubated with $5 \mu \mathrm{M}$ compounds I-III and cisplatin. Figure 5 illustrates the kinetics of platinum accumulation by MCF-7 cells. After $15 \mathrm{~s}$ drug exposure, no platinum was associated with the cells. In contrast to compound III and cisplatin, in the case of the diastereoisomers (compounds I and II), platinum was selectively accumulated with high specificity. For the racemate (compound I), accumulation was very rapid, with an intracellular platinum concentration of $68 \mu \mathrm{mol} \mathrm{l}^{-1}$ being reached within $4 \mathrm{~h}$. The platinum concentration for meso-configurated compound II amounted to $15 \mu \mathrm{mol} 1^{-1}$, whereas that for both the meso-configurated compound III $\left(3.3 \mu \mathrm{mol} \mathrm{l}^{-1}\right)$ and cisplatin $(2.1 \mu \mathrm{mol} \mathrm{1-1})$ were significantly lower. Although at the end of the experiment, the amount of cell-associated platinum resulting from treatment of the cells with compound III was lower than that resulting for incubation with cisplatin, the initial accumulation of platinum by the cells was faster following incubation with compound III (cf. Fig. 5B). 

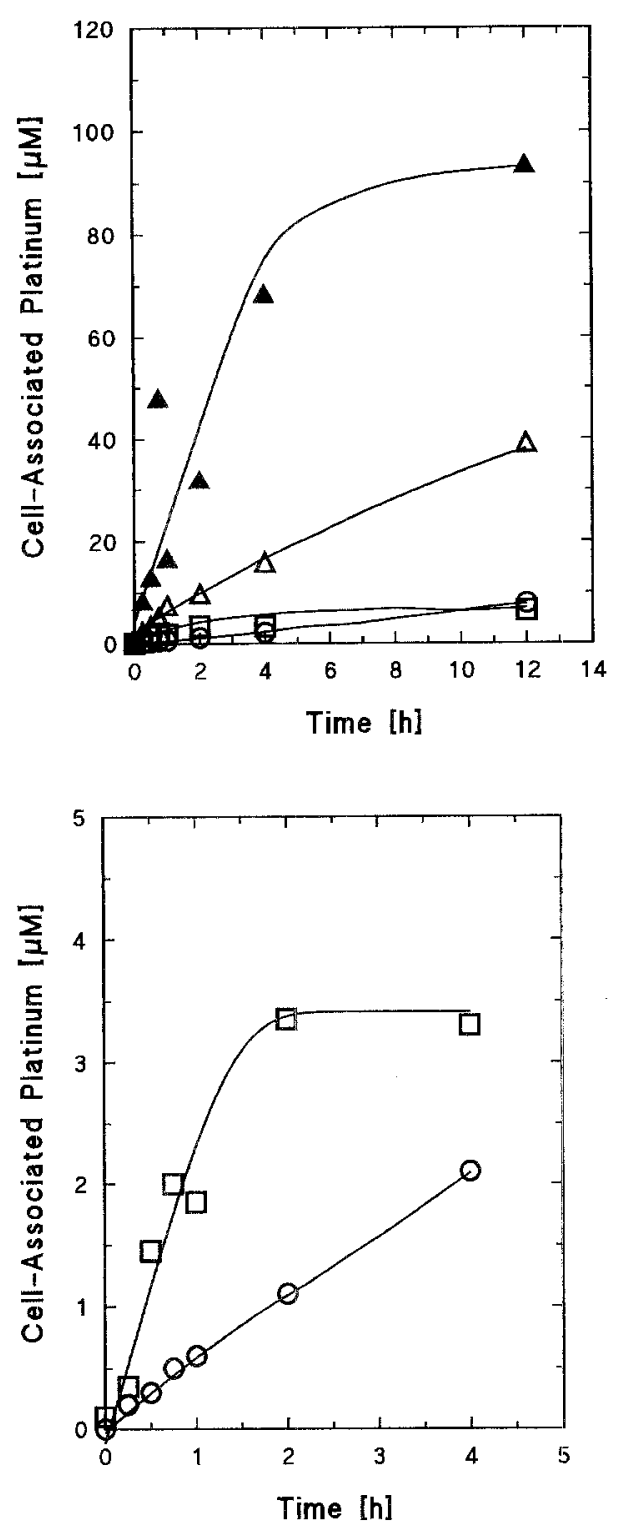

Fig. 5 A, B. Platinum accumulation by MCF-7 cells (passage 160), The cultures were treated with $5 \mu \mathrm{M}$ platinum complex in MEM Eagle's medium containing $10 \%$ FCS. Platinum accumulation is shown on the basis of the mean intracellular concentration expressed in $\mu \mathrm{mol} \mathrm{I}^{-1}$. A $\mathbf{A}$, Raceme-diaqua[1,2-bis(4-fluorophenyl)ethylenediamine]platinum(II) sulfate (compound I); $\triangle$, meso-diaqua[1,2-bis(4-fluorophenyl)ethylenediamine]platinum(II) sulfate (compound II); $\square$, meso-diaqua[1,2bis(2,6-dichloro-4-hydroxyphenyl)ethylenediamine]platinum(II) sulfate (compound III); $O$, cisplatin. B Comparison of initial platinum accumulation after treatment with meso-diaqua[1,2-bis(2,6-dichloro-4-hydroxyphenyl)ethylenediamine]platinum(II) sulfate (compound III, $\square$ ) and cisplatin (O)

\section{DNA platination}

To understand the missing overall difference in the cytotoxicity of cisplatin vs compound I (although the latter was strongly accumulated), we determined the platinum content of DNA after the exposure of MCF-7 cells to each of the four complexes. In Table 1, the results of this experiment are summarized as mean values for the number of base pairs per platinum atom. The base pair/platinum ratios after $4 \mathrm{~h}$ exposure were 17,500 for compound I (high degree of platination), 415,000 for compound II, 99,400 for cisplatin, and 1,140,000 for compound III (low degree of platination). In contrast to all of the other complexes, for which the extent of DNA platination increased with time, the reaction of compound I with DNA was quite rapid (i.e., the degree of platination was maximal after $4 \mathrm{~h}$ ). Surprisingly, after $24 \mathrm{~h}$, only a 1.3-fold difference in DNA-associated platinum was found for cisplatin vs compound III, although the latter was ineffective (cf. Fig. 2) and was not accumulated by the cells (see Fig. 5).

\section{Discussion}

The present study revealed vast differences in the activity of the investigated stereoisomeric diaqua(1,2-diphenylethylenediamine)platinum(II) sulfates and cisplatin against the estrogen-receptor-positive human MCF-7 breastcancer cell line. Wheres compound I, compound II, and cisplatin inhibited cell proliferation in a dose-dependent manner, compound III was ineffective at even an extremely high $\left(10 \mu \mathrm{mol}^{-1}\right)$ dose following long-term drug exposure $(231 \mathrm{~h})$. This observation contrasts with the results of previous studies, in which this estrogenic platinum complex displayed selective and highly reproducible inhibition of estrogen-receptor-positive, ovarian-dependent rodent breast cancers [14, 29]. Cisplatin and both of the diastereoisomeric diaqua[1,2-bis(4-fluorophenyl)ethylenediamine]platinum(II) sulfates (compounds I and II) were equiactive at the 5- $\mu \mathrm{M}$ concentration (Fig. 2), although their onset of action differed. A maximal effect

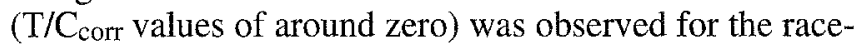
mate (compound I) after about $90 \mathrm{~h}$, for cisplatin after about $200 \mathrm{~h}$, and for the meso-configurated compound II after more than $230 \mathrm{~h}$ incubation.

This phenomenon could be ascribed to a variation of the extent or rate of inactivation of the drugs resulting from reactions with nucleophiles (e.g., amino acids or serum proteins) in the culture medium. It should be borne in mind that in experiments involving prolonged drug-exposure periods, the theoretical concentration-time product $(c \times t$ value) is equal to the actual $c \times t$ value only if the drugs retain their full activity at $37^{\circ} \mathrm{C}$ over the entire exposure period and the response is linear with time. Differences in reactivity would cause different levels of effective concentration during the course of the chemosensitivity assay. In analogy to the pharmacokinetic principle of the equieffectiveness of equal areas under the curve, identical $c \times t$ values are a prerequisite for intrinsically equiactive drugs. Therefore, a decrease in activity due to a lowered effective concentration would be compensated by a prolongation of the exposure period.

To test this hypothesis, cisplatin and compounds I and II were preincubated with culture medium for various intervals under standard conditions (Fig. 3). After $6 \mathrm{~h}$ incubation in medium, cisplatin was fully active, whereas a complete loss of activity was observed after $48 \mathrm{~h}$ incubation in medium containing $10 \%$ FCS. These findings are consistent with stability data for cisplatin described in the 
literature [35]. In comparison with cisplatin, the inactivation of diastereoisomers I and II was faster, with a loss of about $30 \%$ of their inhibitory activity being observed after $6 \mathrm{~h}$ preincubation. Although it is possible that a chloride ligand in cisplatin might in some cases be directly displaced through a reaction with a macromolecule, it is generally agreed that the more common pathway involves an initial aquation reaction in which a chloride is replaced by a water molecule [22]. In water, the equilibrium constant of the first aquation reaction is $4.4 \mathrm{mM}$ at a temperature of $37^{\circ} \mathrm{C}$ and a $t_{1 / 2}$ value of $2.5 \mathrm{~h}$. These values indicate that for $4.4 \mathrm{~mm}$ cisplatin in water, an equilibrium ratio of $1: 1$ for the dichloro:chloroaquo species is eventually reached after $2.5 \mathrm{~h}$. Because of the slowness of this reaction and the presence of reactive constituents other than water, it is highly unlikely that equilibrium would be approached in biological fluids [22]. In blood plasma and in culture medium, the high chloride concentration keeps cisplatin predominantly in the uncharged and relatively nonreactive dichloro form, which guarantees its stability for at least $6 \mathrm{~h}$ (cf. Fig. $3 \mathrm{~A}$ ). Inactivation of the highly reactive diaqua[1,2-bis(4-fluorophenyl)ethylenediamine]platinum (II) sulfates through reactions with medium components is obvious, since no aquation step is required. However, in terms of reactivity, diastereoisomeric compounds I and II were identical. Therefore, inactivation processes cannot explain the striking difference in the manifestation of drug action (Fig. 2B, C).

Because of the relatively fast inactivation of compounds I and II, the lesions that eventually cause inhibition of cell proliferation and cell death would have to arise within the first few hours of the chemosensitivity assay. To test this hypothesis, the antitumor activity of cisplatin, compound I, and compound II was compared as a function of the duration of drug exposure. Figure 4 illustrates that all of the platinum complexes produced a gradual decrease in $\mathrm{T} / \mathrm{C}_{\mathrm{corr}}$ values with increasing time of drug exposure, and a maximal effect (i.e., the same as that observed after permanent drug exposure for $231 \mathrm{~h}$ ) was observed as early as after about $12 \mathrm{~h}$. It is surprising that cisplatin and the racemate (compound I) were equiactive when the cells were treated for $6 \mathrm{~h}$, despite the relative instability of compound $\mathrm{I}$ in culture medium. Since there was no difference in the reactivity of the diastereoisomeric counterparts (compounds I and II), the delayed manifestation of the action of complex II is not likely to originate from a lower platination rate of the target molecule DNA due to steric hindrance of the meso-configurated compound II (cf. Fig. 1), as has previously been assumed [24].

In this context, penetration of the platinum complexes into the tumor cell seemed to be a critical factor. The above-described equilibrium reaction of cisplatin may be of pharmacological importance not only because of the high reactivity of the aquated species but also due to the different ionic states that may affect the drug's ability to penetrate lipid membranes [22]. The uncharged species, including the dichloro and chlorohydroxy complexes, would be expected to enter the cell by passive diffusion $[10,21]$. Nevertheless, conflicting reports have appeared in the literature regarding the mechanism of cisplatin uptake [1]. Byfield and Calabro-Jones [8] reported that cisplatin uptake may be carrier-mediated, but this evidence was indirect. It has also been suggested that cisplatin may be transported into the kidney by the organic cation-transport system [26,34]. A specific uptake of the positively charged compounds I and II by similar carrier mechanisms could explain the differences observed in the antitumor activity of the diastereoisomers due to their stereochemical characteristics.

Comparative uptake studies (Fig. 5) using cisplatin and compounds I-III revealed vast differences in platinum accumulation. We found that no measurable platinum was associated with MCF-7 cells after the platinum complexes had been removed at $15 \mathrm{~s}$ following their addition to the culture flasks, indicating a lack of immediate surface binding of the drugs to these cells. A kinetic investigation of the reaction of the diastereoisomeric compounds I and II $(3 \mu \mathrm{M}$ ) with $3.4 \mathrm{mg}$ human serum albumin/ml buffer (concentrations comparable to the situation in the uptake experiments) revealed that both compounds bound avidly to serum protein within the 1 st hour (data not shown). Due to the great excess of serum proteins as compared with cellular surface protein and to the identical reactivity of the diaqua(1,2-diphenylethylenediamine)platinum(II) complexes I and II, surface reactions are highly unlikely, although from these studies one cannot distinguish between binding of the drugs to cell-surface components and true uptake.

For the diastereoisomeric compounds I and II, platinum accumulation was high as compared with that found for both the meso-configurated platinum complex III and cisplatin. In the case of compound $\mathrm{I}$, the platinum associated with MCF-7 cells amounted to about $93 \mu$ M (cf. Fig. 5A). The platinum uptake for compound I was highly specific and faster than that observed for its meso-configurated counterpart compound II. This discrepancy between the diastereoisomers supports the supposition that the uptake of the diastereoisomeric diaqua[1,2-bis(4-fluorophenyl)ethylenediamine]platinum(II) sulfates by MCF-7 cells is carrier-mediated. The plateau of the platinum-uptake curves after prolonged incubation could be explained by damage of the carrier protein as a result of platination. The specificity seems to be coupled to the three-dimensional structure of the 1,2-bis(4-fluorophenyl)ethylenediamine ligand, since the cellular accumulation of the structurally closely related platinum complex III (cf. Fig. 1) was rather poor. However, in comparison with cisplatin, the platinum accumulation found for compound III was initially faster (see Fig. 5B), which may reflect different mechanisms of uptake.

Although the differences observed in the onset of inhibition of cell proliferation by the cisplatin analogues could partly be explained by different platinum-accumulation velocities, cytotoxicity was not directly correlated with platinum uptake. On the one hand, the low capacity of the estrogen-receptor-positive MCF-7 cell line for the accumulation of meso-diaqua[1,2-bis(2,6-dichloro-4-hydroxyphenyl)ethylenediaminelplatinum(II) sulfate (compound III) would be consistent with the ineffectiveness of this compound, and on the other, cisplatin and the diastereoisomeric complexes I and II exhibited equiactivity despite the striking differences observed in the cellular 
association of platinum resulting from the incubation of cells with these compounds (cf. Fig. $5 \mathrm{~A}$ ).

In addition, the differences in antitumor activity are not completely explainable by the degree of DNA platination caused by the particular compound (see Table 1). Early events in DNA platination seem to produce the critical lesions (intra- or interstrand cross-links), finally resulting in lethal damage. Although we have recently demonstrated that in a solution containing sulfate as the only anion [15], positively charged platinum complexes are accumulated by breast cancer cells, the identification of the species transported in complex media and investigations relating the mechanism of drug uptake and DNA platination to DNA repair should give us a more thorough understanding of this multifaceted phenomenon. Provided that effective plasma levels can be maintained for about $6 \mathrm{~h}$, racemediaqua[1,2-bis(4-fluorophenyl)ethylenediamine]platinum(II) sulfate (compound I) should be superior to cisplatin in the treatment of human MCF-7 breast tumors transplanted into nude mice.

Acknowledgements. The authors wish to thank Ms. E. Deml, Dr. R. Müller and Mr. P. Richthammer for kindly providing the platinum complexes and Ms. P. Pistor for her excellent technical help.

\section{References}

1. Andrews PA, Sriharsha V, Mann SC, Howell SB (1988) cis-Diamminedichloroplatinum(II) accumulation in sensitive and resistant human ovarian carcinoma cells. Cancer Res 48: 68-73

2. Bernhardt $G$, Reile $H$, Birnböck $H$, Spruß T, Schönenberger $H$ (1992) Standardized kinetic microassay to quantitate differential chemosensitivity based on proliferative activity. J Cancer Res Clin Oncol 118: 35-43

3. Bernhardt G, Spruß T, Rustler M (1992) Comparison of MCF-7 and ZR-75-1 cell lines as models for studying hormone-dependent human breast cancer in nude mice. In: Fiebig HH, Berger DP (eds) Immunodeficient mice in oncology. Karger, Basel (in press)

4. Boyer RF (1986) Modern experimental biochemistry. Benjamin Cummings, Menlo Park, California, pp 437-446, 479-488

5. Bradford MM (1976) A rapid and sensitive method for the quantitation of microgram quantities of protein utilizing the principle of protein-dye binding. Anal Biochem 72: $248-254$

6. Brown DB, Khokhar AR, Hacker MP, McCormack JJ (1982) Synthesis and antitumor activity of platinum complexes containing neutral and protonated amino-olefin ligands. Inorg Chim Acta 67: $45-52$

7. Brown DB, Khokhar AR, Hacker MP, Lokys L, Burchenal JH, Newman RA, McCormack JJ, Frost D (1982) Synthesis and antitumor activity of new platinum complexes. J Med Chem 25: 952-956

8. Byfield JE, Calabro-Jones PM (1981) Carrier-dependent and -independent transport of anticancer alkylating agents. Nature 294: $281-283$

9. Fichtinger-Schepman AMJ, Oosterom AT van, Lohman PHM, Berends F (1987) cis-Diamminedichloroplatinum(II)-induced DNA adducts in peripheral leukocytes from seven cancer patients: quantitative immunochemical detection of the adduct induction and removal after a single dose of $\mathrm{cis}$-diamminedichloroplatinum(II). Cancer Res 47: $3000-3004$

10. Gale GR, Morris CR, Atkins LM, Smith AB (1973) Binding of an antitumor platinum compound to cells as influenced by physical factors and pharmacologically active agents. Cancer Res 33: $813-818$
11. Gulotti M, Pasini A, Ugo R, Filippeschi S, Marmonti L, Spreafico F (1984) Enantiomeric cisplatin analogues: an investigation on their activity towards tumors in mice. Inorg Chim Acta 91: 223-227

12. Hay RJ (1988) The seed stock concept and quality control for cell lines. Anal Biochem 171: 225-237

13. Hydes PC (1984) Synthesis and testing of platinum analogues - an overview. In: Hacker MP, Douple EB, Krakoff IH (eds) Platinum coordination complexes in cancer chemotherapy. Martinus Nijhoff, Boston, pp 216-227

14. Karl J, Gust R, Spruss T, Schneider MR, Schönenberger H, Engel J, Wrobel K-H, Lux F, Trebert Haeberlin S (1988) Ring-substituted [1,2-bis(4-hydroxyphenyl)ethylenediamine]dichloroplatinum(II) complexes: compounds with a selective effect on the hormone-dependent mammary carcinoma. J Med Chem 31: $72-83$

15. Koch M, Bernhardt G (1991) Differential accumulation of stereoisomeric [1,2-bis(fluorophenyl)ethylenediamine]platinum(II) complexes by human breast cancer cells in vitro. J Cancer Res Clin Oncol 117 (Suppl 3): 104

16. Köpf-Maier P, Köpf H, Neuse EW (1984) Ferricenium complexes: a new type of water soluble antitumor agent. J Cancer Res Clin Oncol 108: $336-340$

17. Lux F, Trebert-Haeberlin S, Erhardt W (1986) Neutronenaktivierungsanalytische Bestimmung des Chromgehaltes von Laboratoriumskaninchen-Skelettmuskel. Fresenius $Z$ Anal Chem 323: $833-838$

18. Müller R, Gust R, Jennerwein M, Reile H, Laske R, Krischke W, Bernhardt G, Spruss T, Engel J, Schönenberger H (1989) Tumor-inhibiting [1,2-bis(fluorophenyl)ethylenediamine]platinum(II) complexes: I. Synthesis. Eur J Med Chem 24: 341-348

19. Nicolini M (ed) (1988) Platinum and other metal coordination compounds in cancer chemotherapy. Martinus Nijhoff, Boston

20. Noji M, Gohchi Y, Kidani Y (1984) Preparation of antitumor platinum(II) complexes of 1,2-diphenylethylenediamine isomers and their interaction with DNA and its purine moieties. Chem Biol Interact $51: 37-48$

21. Pinto AL, Lippard SJ (1985) Binding of the antitumor drug cis-diamminedichloroplatinum(II) (cisplatin) to DNA. Biochim Biophys Acta 780: $167-180$

22. Reed E, Kohn KW (1990) Platinum analogues. In: Chabner BA, Collins JM (eds) Cancer chemotherapy, principles and practice. J.B. Lippincott, Philadelphia, pp 465-490

23. Reile H, Birnböck H, Bernhardt G, Spruß T, Schönenberger H (1990) Computerized determination of growth kinetic curves and doubling times from cells in microculture. Anal Biochem 187: $262-267$

24. Reile H, Müller R, Gust R, Laske R, Krischke W, Bernhardt G, Spruß T, Jennerwein M, Engel J, Seeber S, Osieka R, Schönenberger H (1990) Tumor-inhibiting [1,2-bis(fluorophenyl)ethylenediamine]platinum(II) complexes: II. Biological evaluation - in vitro studies on the P388 D leukemia cell line. Arch Pharm (Weinheim) 323: $133-140$

25. Reile H, Spruß T, Müller R, Gust R, Bernhardt G, Schönenberger H (1990) Tumor-inhibiting [1,2-bis(fluorophenyl)ethylenediamine]dichloroplatinum(II) complexes: III. Evaluation of mammary tumorinhibiting properties. Arch Pharm (Weinheim) 323: 301-306

26. Safirstein R, Miller P, Guttenplan JB (1984) Uptake and metabolism of cisplatin by rat kidney. Kidney Int 25: 753-758

27. Schneider MR, Schiller C-D, Humm A, Spruß T, Schönenberger H, Amselgruber W, Sinowatz F (1989) [1,2-bis(2,6-dichloro-4-hydroxyphenyl)ethylenediamine]dichloroplatinum(II): an endocrineactive platinum complex with a specific prostatic tumor-inhibiting activity. Prostate 15: 135-148

28. Soule HD, Vazques J, Long A, Albert S, Brennan M (1973) A human cell line from a pleural effusion derived from a breast carcinoma. J Natl Cancer Inst 51: 1409 _ 1416

29. Spruß T, Gust R, Müller R, Engel J, Schönenberger H (1990) Mammary tumor-inhibiting properties of the (S,S)-configurated [1,2-bis(4-hydroxyphenyl)ethylenediamine]dichloroplatinum(II) complex. Arch Pharm (Weinheim) 323:99-102 
30. Spruß T, Bernhardt G, Schickaneder E, Schönenberger H (1991) Different response of murine and human mammary tumor models to a series of diastereoisomeric [1,2-bis(difluorophenyl)ethylenediamine]dichloroplatinum(II) complexes. J Cancer Res Clin Oncol 117: $435-443$

31. Staquet MJ, Byar DP, Green SB, Rozencweig M (1983) Clinical predictivity of transplantable tumor systems in the selection of new drugs for solid tumors: rationale for a three-stage strategy. Cancer Treat Rep 67: $753-765$

32. Trebert-Haeberlin S, Lux F, Karl J, Spruß T, Schönenberger H (1987) Determination of platinum and biologically important trace elements in structure-activity relationship studies on platinum-containing anti-cancer drugs. Special procedures for removing ${ }^{32} \mathrm{P}$ as well as for the estimation of ${ }^{99} \mathrm{Mo}$ and ${ }^{199} \mathrm{Au}$. J Radioanal Nucl Chem 113: $461-467$
33. Wappes B, Jennerwein M, Angerer E von, Engel J, Schönenberger H, Brunner H, Schmidt M, Berger M, Schmähl D, Seeber S (1984) The tumor-inhibiting effect of isomeric dichloro(diphenylethylenediamine)platinum(II) complexes. J Cancer Res Clin Oncol 107: 15-20 34. Williams PD, Hottendorf GH (1985) Effect of cisplatin on organic ion transport in membrane vesicles from rat kidney cortex. Cancer Treat Rep 69:875-880

35. Wilson AP (1986) Cytotoxicity and viability assays. In: Freshney RI (ed) Animal cell culture, a practical approach. IRL Press, Oxford Washington D.C., p 191 